\title{
O pregão eletrônico como instrumento para a garantia do princípio da eficiência na administração pública brasileira
}

\author{
The electronic auction as an instrument to ensure the principle of efficiency in the brazilian public \\ administration \\ El pregón electrónico como instrumento para garantizar el principio de eficiencia en la \\ administración pública brasileña
}

Recebido: 13/07/2021 | Revisado: 19/07/2021 | Aceito: 22/07/2021 | Publicado: 29/07/2021

Ederluiz Martins

ORCID: https://orcid.org/0000-0003-3729-8245

Universidade Federal dos Vales do Jequitinhonha e Mucuri, Brasil E-mail: ederluiz.martins@ufvjm.edu.br

Gabriella Carlos Oliveira

ORCID: https://orcid.org/0000-0002-5496-2200

Universidade Federal dos Vales do Jequitinhonha e Mucuri, Brasil E-mail: gabriellacarloso@ hotmail.com

Ricardo Lorrane Azevedo Souza

ORCID: https://orcid.org/0000-0003-3582-6083

Universidade Federal dos Vales do Jequitinhonha e Mucuri, Brasil E-mail: ricardo.azevedo@ufvjm.edu.br

Ciro Meneses Santos

ORCID: https://orcid.org/0000-0001-8687-0987 Universidade Federal dos Vales do Jequitinhonha e Mucuri, Brasil E mail: cirosantos@gmail.com

Marcio Coutinho de Souza

ORCID: https://orcid.org/0000-0002-4238-1572 Universidade Federal dos Vales do Jequitinhonha e Mucuri, Brasil E-mail: marcio.souza@ufvjm.edu.br

Naldeir dos Santos Vieira

ORCID: https://orcid.org/0000-0001-5624-8345

Universidade Federal dos Vales do Jequitinhonha e Mucuri, Brasil E-mail: naldeir.vieira@ufvjm.edu.br

\begin{abstract}
Resumo
As transformações sofridas pela Administração Pública com o passar dos anos trouxeram reflexos em todas as atividades administrativas realizadas por seus agentes. Dentre elas, cabe destacar as ocorridas na forma em que são realizadas as compras públicas, tendo em vista a observância do princípio da eficiência da Administração Pública. Neste âmbito, o Pregão Eletrônico, considerado pela dicção do Decreto no 10.024/2019 como obrigatório para todos os órgãos da administração pública federal, é a ferramenta mais moderna utilizada. Assim, objetiva-se neste ensaio teórico caracterizar o pregão eletrônico, como instrumento para garantia da eficiência administrativa, utilizando-se da abordagem qualitativa. Para tanto, no primeiro semestre do ano de 2021, foram identificados estudos relacionados ao tema, disponíveis em plataformas eletrônicas de conteúdo indexado. Dentre os resultados, foi identificado que o pregão eletrônico potencializa a efetividade do princípio da eficiência na administração pública, diante da celeridade, transparência otimização dos custos e benefícios obtidos nos processos de compras. Cabe destacar a presença da inversão de fases neste processo licitatório, onde, primeiramente, se julga as propostas e, posteriormente, analisa os documentos das empresas vencedoras.
\end{abstract}

Palavras-chave: Pregão eletrônico; Princípio da eficiência; Administração pública.

\begin{abstract}
The transformations undergone by the Public Administration over the years have reflected on all administrative activities performed by its agents. Among them, it is worth highlighting those that have occurred in the way public purchases are made, in view of the compliance with the principle of efficiency of the Public Administration. In this context, the Electronic Auction, considered by the diction of Decree No. 10.024/2019 as mandatory for all organs of the federal public administration, is the most modern tool used. Thus, this theoretical essay aims to characterize the electronic auction, as a tool to ensure administrative efficiency, using the qualitative approach. To this end, in the first half of the year 2021, studies related to the theme were identified, available on electronic platforms of indexed content. Among the results, it was identified that the electronic auction enhances the effectiveness of the principle of efficiency in public administration, due to the speed, transparency and optimization of costs and benefits obtained in
\end{abstract}


the procurement processes. It is worth noting the presence of the inversion of phases in this bidding process, where the proposals are first judged and then the documents of the winning companies are analyzed.

Keywords: Electronic auction; Efficiency principle; Public administration.

\begin{abstract}
Resumen
Las transformaciones sufridas por la Administración Pública a lo largo de los años trajeron reflejos en todas las actividades administrativas realizadas por sus agentes. Entre ellas, cabe destacar las que se produjeron en la forma de realizar las compras públicas, de cara al cumplimiento del principio de eficiencia de la Administración Pública. Dentro de este ámbito, la Subasta Electrónica, considerada por la dicción del Decreto N. ${ }^{\circ}$ 10.024/2019 como obligatoria para todos los órganos de la administración pública federal, es la herramienta más moderna utilizada. Así, se pretende en este ensayo teórico caracterizar el pregón electrónico, como instrumento para garantizar la eficiencia administrativa, utilizando el enfoque cualitativo. Para ello, en el primer semestre del año 2021, se identificaron estudios relacionados con el tema, disponibles en plataformas electrónicas de contenido indexado. Entre los resultados, se identificó que el pregón electrónico potencia la eficacia del principio de eficiencia en la administración pública, frente a la rapidez, transparencia y optimización de los costes y beneficios obtenidos en los procesos de contratación. Cabe destacar la presencia de la inversión de fases en este proceso de licitación, donde, primero, se juzgan las propuestas y luego se analizan los documentos de las empresas ganadoras.
\end{abstract}

Palabras clave: Subasta electrónica; Principio de eficiencia; Administración pública.

\title{
1. Introdução
}

De modo geral, o processo de compra e venda não é complexo, se restringe ao ato de receber uma determinada mercadoria diante de uma contrapartida correspondente, que previamente foi acordada (Marrara, 2014 \& Medauar, 2018). No entanto, para a administração pública brasileira, a forma de comprar deve obedecer aos ditames legais e principiológicos para tal ação (Marrara, 2014 \& Medauar, 2018). Isto se deve ao fato de que o administrador público, responsável pelos procedimentos de aquisição e contratos, não é o dono dos bens e serviços que serão adquiridos (Marrara, 2014 \& Medauar, 2018). Na administração pública, a parte principal é a sociedade como um todo, sendo esta a verdadeira dona dos bens e serviços por aquela adquirida (Marrara, 2014 \& Medauar, 2018). Assim, é imprescindível que os atos praticados pelo Poder Público estejam de acordo com o que está disposto no ordenamento jurídico, diante da premissa de este se orienta pela defesa dos interesses coletivos (Marrara, 2014 \& Medauar, 2018).

No entanto, nem sempre a administração pública brasileira esteve no formato atual. Para Campelo (2010) a administração pública passou por pelo menos três transformações distintas, sendo elas: a patrimonialista, a burocrática e a gerencial. A patrimonialista tinha muito característico o clientelismo, com troca de favores e prevalecimento de interesse privado em detrimento do público (Campelo, 2010). Na transformação burocrática foram implantados controles rígidos no intuito de inviabilizar a forma patrimonialista da gestão, sendo definidos e implementados princípios para a racionalidade e profissionalização das ações. No entanto, esse modelo, com o passar do tempo, não se mostrou eficiente diante de novas alterações na dinâmica social (Campelo, 2010).

Com as novas demandas sociais, o Estado substituiu o modelo burocrático por um modelo voltado para a eficiência, descentralização e excelência do serviço público, que se apoia nas correntes teóricas do neoinstitucionalismo, do gerencialismo e da boa governança, para promover uma renovação na administração pública (Bresser-Pereira, 2008 \& Paes De Paula, 2005 \& Andion, 2012). Este modelo refere-se à administração pública gerencial. Entre as mudanças trazidas por essa reforma, foram feitas mudanças legais, principalmente com as Emendas Constitucionais n ${ }^{\circ} 19$ e 20, que fizeram alterações no teto de gasto do funcionalismo, no Regime Jurídico Único e a positivação do princípio da eficiência (Abrucio, 2007).

O princípio da eficiência está diretamente relacionado a persecução do bem comum, pelos agentes da administração pública, direta e indireta, que devem agir de forma imparcial, transparente, participativa, eficaz e com qualidade, primando pelo melhor uso dos recursos públicos e pela redução de desperdícios (Moraes, 1999). Foi nesta lógica, que foi instituído o Pregão Eletrônico na efetivação de compras públicas (Moraes, 1999).

O pregão como modalidade de licitação foi instituído pela Lei $\mathrm{n}^{\circ} 10.520 / 02$, sendo que o Decreto $\mathrm{n}^{\circ} 5.450 / 2005$, 
regulamentou na forma eletrônica e coube aos municípios a regulamentação nas suas legislações locais (Cavalcante \& et al., 2017). Esta modalidade passa a ser utilizada obrigatoriamente nas licitações para aquisição de bens e serviços comuns, sendo preferencial a utilização na sua forma eletrônica (Cavalcante \& et al., 2017). Neste cenário, para se alcançar meios mais eficientes da atividade licitatória é importante que os municípios se adequem a essa nova modalidade (Araújo \& Othon, 2015).

Em 20 de setembro de 2019, o Governo Federal publicou o Decreto no 10.024 que regulamenta a licitação, o pregão na forma eletrônica, para a aquisição de bens e a contratação de serviços comuns, bem como revoga os decretos 5.450 e 5.504 , ambos de 2005 (Brasil, 2005 \& Brasil, 2019). Entende-se pela dicção do artigo primeiro deste decreto que a utilização do Pregão Eletrônico é obrigatória para os órgãos da administração pública federal. Em decorrência disto, foi editada a Instrução Normativa n 206/2019, que estabeleceu prazos para que os outros entes da federação utilizem o Pregão Eletrônico.

Dessa forma, surge o seguinte problema de pesquisa:

- Quando observado o princípio da eficiência, como a administração pública pode se beneficiar das ferramentas proporcionadas pelo pregão eletrônico?

Os órgãos da Administração Pública vinham apresentando muita resistência na utilização do Pregão na forma Eletrônica, uma vez que o habitual era na forma presencial (Araújo \& Othon, 2015). Com a imposição da obrigatoriedade, o mesmo passou a ser utilizado com mais frequência, fazendo com que ficasse evidente que, além de ampliar a competitividade entre os licitantes, o procedimento se tornasse mais transparente e eficiente, sendo que a eficiência é um dos princípios basilares da Administração pública (Araújo \& Othon, 2015).

Diante dessa premissa, o presente estudo, de caráter teórico, objetivou caracterizar o pregão eletrônico tendo em vista a garantia do princípio da eficiência na Administração Pública. Utilizou-se da abordagem qualitativa, devido à natureza exploratória do estudo ancorada em pesquisa bibliográfica, principalmente de doutrinas e legislações pertinentes.

Esta pesquisa evidencia um tema de grande relevância acadêmica, social, administrativa e jurídica, considerando a tendência de ampliação da utilização do Pregão eletrônico. Contudo, em razão de suas limitações, principalmente metodológicas, não tem por pretensão esgotar a matéria, mas apenas ser mais um ponto de reflexão, capaz de lançar luzes para melhor entendimento da temática. Para tanto, o presente artigo está dividido em quatro seções. A primeira irá tratar da Administração Pública. A segunda dos princípios constitucionais, para depois adentrar na contextualização histórica da licitação. A terceira seção, especificamente, trata do pregão eletrônico. Na quarta seção é apresentada uma análise interpretativa quanto a utilização do pregão eletrônico com base na análise das publicações pela administração pública tendo em vista a eficiência.

\section{Metodologia}

O presente estudo foi desenvolvido a partir de uma pesquisa bibliográfica, tendo caráter teórico, qualitativo e exploratório. "A pesquisa bibliográfica procura explicar um problema a partir de referências teóricas publicadas [...] (Cervo, Bervian \& Da Silva, 2007, p. 60). Pode proporcionar um "acervo de informações sobre livros, artigos e demais trabalhos que existem sobre determinados assuntos, dentro de uma área de saber" (Severino, 2002, p. 39). Dessa forma, busca-se conhecimento a partir de materiais bibliográficos dentro da área que envolve a Administração Pública.

A pesquisa exploratória, juntamente com a bibliográfica, colaborou para um melhor embasamento da pesquisa. Segundo Cervo, Bervian \& Da Silva (2007) esse tipo de pesquisa, pode fornecer uma melhor compreensão e familiaridade com a temática. Esse direcionamento proporcionado pela pesquisa exploratória pode auxiliar para as descrições mais precisas da situação problema visando descobrir possíveis relações existentes entre esses vários elementos, componentes ou partes (Cervo, Bervian \& Da Silva, 2007).

Assim, na busca por material bibliográfico para desenvolver esse artigo, os autores, pesquisaram em sites e base de 
dados (Google Acadêmico, Web of Science, entre outros), esses possibilitaram encontrar Leis, teses, dissertações e artigos em revistas específicas da área, bem como, em outras revistas. Como critério de busca e seleção do material bibliográfico, os termos principais utilizados foram: administração pública, princípios constitucionais, princípio da eficiência, licitação e pregão eletrônico.

No diálogo qualitativo com os termos pesquisados foi realizada uma análise interpretativa mostrada ao longo de todo o referencial teórico e destacando-se ao final. "Interpretar, em sentido restrito, é tomar uma posição própria a respeito das ideias enunciadas, é superar a estrita mensagem do texto, é ler nas entrelinhas, é forçar o autor a um diálogo, é explorar toda a fecundidade das ideias expostas, é cotejá-las com outras, enfim, é dialogar com o autor" (Severino, 2002, p. 56, grifo do autor). Além disso, a análise interpretativa permite aos autores situar o pensamento desenvolvido sobre cada termo, em uma esfera mais ampla do pensamento geral dos autores (Severino, 2002); verificar, como as ideias expostas sobre os termos pesquisados se relacionam com as posições gerais do pensamento teórico dos autores, tal como é conhecido por outras fontes (Severino, 2002), na expectativa de caracterizar o pregão eletrônico, como instrumento para garantia da eficiência administrativa.

Vale destacar que os estudos que envolvem a Administração Pública per se stante, são muito importantes tendo em vista que "o campo de estudos de administração pública no Brasil [...] transitou por diferentes mudanças paradigmáticas" (Granato, 2018, p. 43).

\section{A Administração Pública no Brasil}

A administração pública brasileira passou por inúmeras transformações, incorporando influências de diferentes correntes teóricas. Campelo (2010) afirma a existência de pelo menos três modelos de administração pública: patrimonialista, burocrática e gerencial. A administração pública patrimonialista é baseada nas ideias do clientelismo, na troca de favores, no prevalecimento de interesses privados em detrimento ao interesse público. Mourão (2015) caracteriza o modelo como uma forma de dominação política na qual não existem claras divisões entre as esferas pública e privada. Não há diferenciação por parte dos governantes e gestores públicos detentores do poder político-administrativo Mourão (2015). A dominação se dá por meio de laços pessoais ou privados Mourão (2015).

Para Campelo (2010), a prática patrimonialista norteia a conduta dos servidores públicos, dos chefes, gerando uma conduta privatista da coisa pública. Por consequência, o espírito do patrimonialismo é envolvido nas próprias instituições e, por vezes, materializado em normas jurídicas. A estrutura assimétrica de direitos e deveres tendem a reproduzir e a naturalizar as desigualdades como: acesso à justiça, aos bens públicos, a produtividade, a educação, saúde, moradia e entre outros. O Estado tem seu caráter público limitado, contribuindo assim com a ineficiência, a má gestão, a corrupção, o clientelismo e a politicagem (Mourão, 2015).

Após o momento histórico que norteou as práticas patrimonialistas, a administração pública passou por um período de enfoque burocrático. Este período não é bem delineado, mas após o reconhecimento da Administração como ciência, destacase as influências de Taylor, através dos trabalhos desenvolvidos na área da administração científica, e de Weber, com a teoria da burocracia (Andion, 2012). As organizações se tornam sistemas sociais racionais e possuem como características o formalismo e a impessoalidade. Dessa maneira, a burocracia se legitima pelo seu caráter racional-legal. Controles rígidos são implementados para inviabilizar as mazelas do modelo patrimonialista e os princípios de profissionalismo, carreira, hierarquia, impessoalidade e formalismo orientam o seu desenvolvimento (Campelo, 2010).

Nessa perspectiva do caráter racional-legal a ideia racionalista ocasionou a criação do Departamento Administrativo do Serviço Público (DASP) para divulgar o conhecimento administrativo (Keinert, 1994). O DASP tinha como objetivo estruturar uma administração pública nos moldes dos países desenvolvidos, implementando o Estado de Bem-Estar (Andion, 2012). Keinert (1994) descreve que o Estado visou implementar a ideologia desenvolvimentista, transformar suas burocracias 
em instrumentos de mudança social e atuar na gestão de grandes organizações para aumentar sua capacidade de intervenção, centralização e controle.

A administração pública utilizou do modelo burocrático na tentativa de ser eficiente, porém, ao longo do tempo seu desempenho piorou por não conseguir acompanhar a complexidade e o dinamismo da sociedade, apresentou sinais de esgotamento e abriu espaço para um processo de reorganização institucional (Keinert, 1994 \& Abreu, Helou \& Fialho, 2013). Assim as organizações públicas passaram a demandar um novo modelo de administração para se tornarem mais eficientes, eficazes, transparentes e com controle orçamentário financeiro (Campelo, 2010). O Estado substituiu o modelo burocrático por um modelo voltado para a eficiência, para a descentralização e para a excelência do serviço público, que se apoia nas correntes teóricas do neoinstitucionalismo, do gerencialismo e da boa governança, para promover uma renovação na administração pública (Bresser-Pereira, 2008 \& Paes De Paula, 2005 \& Andion, 2012). Neste contexto surge o modelo gerencialista, que é fundamentado na "utilização de novos princípios nas relações políticas e administrativas, visando à construção de um novo perfil de Estado - mais eficaz e mais qualificado para a prestação de serviços públicos de qualidade e com menores custos para a sociedade" (Abreu, Helou \& Fialho, 2013, p. 611).

No modelo gerencialista os atores políticos e a sociedade civil passam a participar da administração pública. Há uma intensa mobilização político-social e um processo de reorganização institucional. Atos normativos foram publicados para determinar a adoção de ferramentas gerenciais utilizadas em setores privados (Souza \& et al. 2020). Um novo conceito de desenvolvimento começa a emergir, a equidade e a adequação social ganham ênfase frente a eficiência (Keinert, 1994 \& Andion, 2012). A sociedade civil ganha importância enquanto ator político e passa a participar da administração pública por meio de conselhos, fóruns, comissões de planejamento e outros (Andion, 2012). Keinert (1994) destaca que são características desse período: a democratização, os conflitos de interesses e os recursos escassos, que faz com que a sociedade exija do Estado uma capacidade de gerir e inovar para melhorar a qualidade dos serviços oferecidos a sociedade. Dessa forma, a sociedade vem solidificando a percepção de cidadania, o conhecimento de seus direitos e o encorajamento à cultura democrática.

\section{Dos Princípios Constitucionais}

A Constituição da República Federativa do Brasil de 1988 (CRFB/88) atribuiu ao Estado os poderes da União, independentes e harmônicos entre si, o Legislativo, o Executivo e o Judiciário (Carvalho Filho, 2012). Ao Estado foi concedida a função administrativa, atribuída ao Poder Executivo; a função normativa, atribuída ao Poder Legislativo e; a função jurisdicional, atribuída ao Poder Judiciário. As três funções igualmente importantes para a busca do bem comum da sociedade brasileira (Carvalho Filho, 2012 \& Leite, 2001).

De acordo com Rocha (1995, p. 12) são, "formas específicas de exercício do poder político, previamente determinadas pelo direito, as quais, a juízo do legislador, constituem a estrutura mais adequada para alcançar os objetivos a que o Estado se propõe". A separação dos poderes permite ao Estado a eventualidade de produzir normas inerentes para o cumprimento da execução de autoridade. Ao Poder Executivo é confiada a função administrativa, porém, pode criar normas universais por meio da sua autoridade regulamentadora. Dessa maneira, o Estado emprega a função administrativa para executar seus objetivos (Carvalho Filho, 2012).

O Estado efetiva bem sua função administrativa quando:

Na função administrativa o grande alvo é, de fato, a gestão dos interesses coletivos na sua mais variada dimensão, consequência das numerosas tarefas a que se deve propor o Estado moderno. Como tal gestão implica normalmente a prática de vários atos e atividades alvejando determinada meta, a Administração socorre-se, com frequência, de processos administrativos como instrumento para concretizar a função administrativa (Carvalho Filho, 2012, p. 5).

A administração pública tem a obrigação de atuar regulada na lei para servir as carências comuns e resguardar o 
interesse da sociedade. "Toda atividade material que a lei atribui ao Estado para que a exerça diretamente ou por meio de seus delegados, com o objetivo de satisfazer concretamente às necessidades coletivas, sob regime jurídico total ou parcialmente público" (Di Pietro, 2001, p. 98).

A CRFB de 1988 expõe que os entes federativos são autônomos para se auto-organizar, se autogovernar e se autoadministrar. Isso quer dizer que o ente federativo tem capacidade de conceber seu poder constitutivo, dispor seu governo, escolher seus governantes e organizar suas atividades obrigatórias (Carvalho Filho, 2012). A administração dos interesses comuns deverá ser direcionada aos indivíduos com foco no seu amparo, garantia e satisfação. Para que a administração pública execute seus objetivos são necessários os agentes públicos, pois são eles que executam as funções atribuídas ao Estado (Carvalho Filho, 2012).

Nos artigos 37 e 38 da CRFB/88 são expressas as normas comuns para os servidores públicos. No art. 37 estão definidos os princípios administrativos que guiam a administração pública. "Estes princípios são considerados como a base de toda a atividade administrativa e regulam as ações dos órgãos públicos e de seus administradores e servidores" (Camargo \& Guimarães, 2013, p. 136). Originalmente, foram escritos na constituição os princípios da legalidade, da impessoalidade, da moralidade e da publicidade. Por meio da Emenda Constitucional n 19 de 1998, foi acrescentado o princípio da eficiência. Que visa assegurar uma gestão pública mais eficaz e que permita a realização de metas de forma mais ágil, atingindo o objetivo ao qual se recomenda. Neste sentido, não menos importante, destaca Teixeira et al. (2021, p. 5) "[...] para seguir as práticas de boa governança será necessário o cumprimento inicialmente dos cinco princípios determinados na Constituição Federal no seu Artigo 37 [...]".

A adição do princípio da eficiência permitiu à administração pública priorizar a melhoria da qualidade dos serviços, reduzir custos e implementar uma cultura gerencial centrada em soluções (Camargo \& Guimarães, 2013). De acordo com Morais (2009, p. 100), "os princípios são normas dotadas de positividade, que determinam condutas obrigatórias impedindo a adoção de comportamento com eles incompatível". Eles facilitam o entendimento íntegro das normas e direcionam as significações praticáveis em frente do caso determinado, diante da legitimidade ratificada pelo sistema jurídico (Morais, 2009).

Para Medauar (2011, p. 128) os princípios são importantes "sobretudo para possibilitar a solução de casos não previstos, para permitir melhor compreensão dos textos esparsos e para conferir certa segurança aos cidadãos quanto à extensão dos seus direitos e deveres". Segundo Cury-Mendes (2015, p. 137) “os princípios consistem em sustentáculos do ramo, que se encontram espalhados por todo o ordenamento jurídico brasileiro, podendo ou não estar escritos. Eles são de observância obrigatória no âmbito da Administração Pública Brasileira [...]”.

\subsection{Do princípio da eficiência}

O princípio da eficiência foi introduzido na CRFB/88 por meio da EC 19/1998. Sua finalidade é assegurar uma gestão pública cada vez minimamente burocrática e autorizar a execução de objetivos de modo mais rápido e eficaz para alcançar a finalidade a qual se recomenda. Desde então a administração pública passou a priorizar o aumento da qualidade dos serviços, a redução de custos e a busca de uma cultura gerencial focada em resultados (Pedraja-Chaparro, Salinas-Jiménez \& Smith, 2005). É natural a preocupação com a maior eficiência no setor público devido à escassez de recursos e os gastos crescentes neste setor (Pedraja-Chaparro, Salinas-Jiménez \& Smith, 2005). Para Alcântara (2009), a avaliação da eficiência é de difícil operacionalização, ainda mais em serviços públicos. A maioria das atividades públicas não permitem uma avaliação direta e objetiva dos resultados, pois atuam em sistemas abertos e complexos. A busca por eficiência se dá em conseguir um melhor resultado com os mesmos recursos ou até mesmo com menos recursos.

A eficiência é a procura do equilíbrio entre os custos e benefícios da adoção de políticas públicas, procurando realizar da melhor forma os serviços dos setores públicos, com um custo que seja satisfatório e razoável, procurando não manter 
situações custosas, ou deficitárias para os entes estatais, numa relação que com o menor custo possível possa se atingir os interesses dos cidadãos, no sentido da satisfação da demanda dos mesmos junto à iniciativa pública Camargo e Guimarães (2013, p. 137). Para Camargo e Guimarães (2013, p. 137) o conceito remete "[...] a capacidade de alcançar os objetivos e as metas programadas com o mínimo de recursos disponíveis e tempo, conseguindo desta forma a sua otimização".

Espera-se que o agente público realize o melhor desempenho possível nas suas atribuições para alcançar os melhores resultados. Quanto à Administração Pública, espera-se a capacidade de disciplinar, estruturar e organizar para alcançar melhores resultados na prestação do serviço público (Camargo \& Guimarães, 2013).

As descrições acima concretizam o princípio da eficiência diante das realidades dinâmicas vividas pela administração pública nas execuções de suas atividades à sociedade. Nesse sentido, foi necessário à Administração Pública se adaptar, e "estas transformações foram influenciadas tanto pelas experiências de outros países quanto da administração privada brasileira. Entre estas transformações destaca-se a inclusão do princípio da eficiência" (Martins \& et al., 2021, p. 14).

O princípio da eficiência conduz a administração pública para a melhoria contínua das técnicas de prestação de serviços (Camargo \& Guimarães, 2013). Essas melhorias podem ocorrer através de mecanismos que permitem aos públicos internos e externos da administração pública avaliarem a qualidade do atendimento ou serviço recebido. De acordo com Camargo e Guimarães (2013, p. 141), “a própria administração deve se utilizar de mecanismos adequados para concretizar seus objetivos, tais como: capacitação de agentes públicos; melhoria nos processos administrativos; transparência; racionalização; valorização com base no mérito; produtividade e controle"

Entre os mecanismos utilizados pela administração pública na tentativa de concretizar seus objetivos, está o pregão eletrônico, previsto no Decreto Federal n 10.024/19 que regulamenta a licitação, na modalidade pregão, na forma eletrônica, para a aquisição de bens e a contratação de serviços comuns, incluídos os serviços comuns de engenharia, e dispõe sobre o uso da dispensa eletrônica, no âmbito da administração pública federal.

\section{Contextualização Histórica da Licitação}

O procedimento licitatório originou-se na Idade Média, nos Estados Medievais da Europa através do sistema de "Vela e Pregão" onde o Estado distribuía avisos informativos, marcando local, data, e horário para que os interessados comparecessem a fim de atender as necessidades descritas, momento em que uma vela era acesa dando início ao certame, assim, os participantes ofereciam lances até que a vela se apagasse por si só ou queimasse até o seu final, consequentemente, era considerado o vencedor aquele que ofertasse o último lance de menor preço (Ribeiro, 2007).

Nessa época o modelo adotado de Administração Pública era o Patrimonialismo, uma vez que o objetivo da gestão estava no benefício econômico-social do clero e da nobreza, facilitando assim, a prática de atos de corrupção, empreguismo e nepotismo (Ribeiro, 2007).

Assim, em meados do século XIX - Estado Liberal, surge então a Administração Pública Burocrática com intuito de proteger o Estado da corrupção, substituindo a Administração Patriarcal. Com o surgimento da Administração Pública burocrática, as regras que tratavam de licitação foram aperfeiçoadas (Ribeiro, 2007).

No entanto, com esse novo modelo de Administração Pública, constatou-se que a licitação estava totalmente engessada, com vícios, que contribuíam com a ingerência da máquina pública, fato entre outros que desencadearam o surgimento da Administração Pública gerencial, cujo objetivo era melhorar a gestão dos gastos públicos (Ribeiro, 2007).

No Brasil, o processo licitatório sofreu diversas transformações, sendo introduzida no ordenamento jurídico brasileiro através do Decreto $\mathrm{n}^{\circ}$ 2.926, de 1862 que regulamentava as arrematações de serviços a cargo do Ministério da Agricultura, posteriormente, com o advento de diversas leis que previam o procedimento licitatório, consolidou-se no âmbito federal pelo Decreto nº 4.536 de 1922, a partir do qual foi criado Código de Contabilidade da União. 
De acordo com Cretella Júnior (1999), a partir do referido Código, o procedimento licitatório veio evoluindo com o objetivo de conferir maior eficiência às contratações públicas, sendo, por fim, sistematizado através do Decreto-Lei $n^{\circ} 200$ de 1967, que determinava a reforma administrativa federal e a extensão aos Estados e Municípios.

Nesse sentido, a partir de 1967 a licitação tornou-se um procedimento administrativo preliminar complexo, ao qual recorre a Administração Pública quando, desejando celebrar contrato com o particular, referente a compras, vendas, obras, trabalhos ou serviços, seleciona, entre várias propostas, a que melhor atende ao interesse público, baseando-se para tanto em critério objetivo, fixado de antemão, em edital a que se deu ampla publicidade (Cretella Junior, 1999).

Todavia, o Decreto-Lei n ${ }^{\circ}$ 2300/86, foi o grande marco da licitação no Brasil, tendo em vista que o antigo estatuto jurídico das Licitações e dos Contratos Administrativos marcou profunda e definitivamente seu lugar na história do direito brasileiro, fazendo com que o legislador brasileiro de 1991 a 1993 o prestigiasse na mais ampla medida, elegendo-o como fonte de inspiração para a criação da Lei n ${ }^{\circ}$ 8.666/93 (Rigolin, 2008).

Ademais, com a promulgação da Constituição Federal de 1988, o art. 37, inciso XXI tratou a licitação como princípio constitucional, bem como atribuiu competência legislativa à União para dispor sobre normas gerais de licitação e contratação administrativa, tornando obrigatório o processo licitatório para a aquisição e contratação de serviços e produtos por parte da Administração Pública, sendo regulamentada pela Lei no 8.666, de 21 de junho de 1993, atualmente em vigor.

Ressalta-se que estão submetidos à Lei de Licitações, além dos órgãos da administração direta, os fundos especiais, as autarquias, as fundações públicas, as empresas públicas, sociedades de economia mista e todas as demais entidades controladas direta ou indiretamente pela União, Estados, Distrito Federal e Municípios (Brasil, 1993).

Para Justem Filho (2012), as regras oriundas da Lei no 8.666/1993 são resultados de uma evolução histórica e a consagração de princípios que dão base à Constituição Federal de 1988, atendendo as demandas provenientes de fatos que se desenvolveram no início da década de 1990.

Neste sentido, a Lei $\mathrm{n}^{\circ}$ 8.666/93 que vigora atualmente, tem como mérito as seguintes e principais alterações e aperfeiçoamentos: ampliar a aplicação das normas gerais à Administração dos Estados, do Distrito Federal, dos Municípios e das Entidades Vinculadas; melhor caracterizar o dever geral de licitar e as hipóteses que o excepcionam; traçar definições objetivas sobre figuras que passaram a ocupar posição de relevo na conceituação legal; vincular a administração pública a regras mais exigentes para a elaboração de editais e para o julgamento de propostas; criar procedimentos especiais para o processamento de determinados tipos e regimes de licitação; assegurar o direito à ampla defesa em caso de desfazimento do processo licitatório, por revogação ou anulação (Pereira Júnior, 2003).

É importante destacar que a Lei no 8.666 é do ano de 1993, período em que predominava no país a Administração Pública burocrática, fato que justifica todo esse excesso de formalismo, morosidade e engessamento dos atos administrativos previstos no seu regramento.

Com efeito, a lei em comento contemplou cinco modalidades licitatórias: concorrência, tomada de preços, convite, concurso e leilão. Neste contexto, toda essa evolução legislativa sobre a licitação, possibilitou a adoção de inúmeras inovações, alterando sobremaneira o regime administrativo do Estado brasileiro, como a implantação do modelo gerencial em substituição ao modelo burocrático, caracterizado pelo controle voltado predominantemente para os resultados, na busca por maior transparência nas contratações públicas (Pereira Júnior, 2003).

Assim, diante no novo modelo de administração pública gerencial que foi sendo implantado no país a partir da década de 1990, novas modalidades de contratação pública surgiram, como foi o caso do Pregão, instituído pela Lei ${ }^{\circ}$ 10.520/02, e o Regime Diferenciado de Contratações através da Lei nº 12.462/11. 


\section{Pregão Eletrônico}

Com vistas a melhorar as contratações realizadas pela Administração Pública, foi instituída a Lei 10.520/02, a qual trouxe uma nova modalidade de licitação, denominada pregão, que no Governo Federal foi regulamentado pelos Decretos $\mathrm{n}$. 3555/2000 e n. 5.450/2005, o segundo veio regulamentando o pregão na forma eletrônica e, coube aos estados e municípios regulamentarem por meio de suas legislações locais (Cavalcante \& et al., 2017). Este instrumento veio para permitir a identificação da melhor maneira para adquirir bens e serviços comuns (Araújo \& Othon, 2015).

O Pregão é uma das modalidades mais utilizadas pela Administração Pública em todas as suas esferas, movimentando grande parte dos recursos públicos destinados às aquisições e contratações públicas (Araújo \& Othon, 2015). A modalidade do pregão, em princípio, não pode ser utilizada para a contratação de obras, serviços de engenharia, locações imobiliárias e alienações em geral, já que esses objetos não podem ser considerados de natureza comum, pelo fato de exigirem certo estudo aprofundado devido a sua complexidade técnica, devendo-se, nesses casos, continuar utilizando os demais modelos tradicionais de licitação (Araújo \& Othon, 2015).

É notório o avanço em termos de agilidade nas compras públicas, Araújo \& Othon (2015), dizem ser nítida a praticidade do processo já que as fases da licitação são invertidas, ocorrendo primeiro o julgamento das propostas, ocasião em que é permitida a confrontação direta entre os interessados, mediante apresentação de lances verbais sucessivos até a proclamação do vencedor. Somente depois desses procedimentos é iniciada a fase de habilitação, na qual se verifica a documentação apenas do fornecedor mais bem qualificado. Na licitação tradicional, o procedimento se desenrola de modo inverso, gerando, no mínimo, grande desperdício de tempo. Outra vantagem do pregão é que, por seu intermédio, somente poderão ser adquiridos bens e contratados serviços comuns, assim entendidos aqueles cujos padrões de qualidade possam ser objetivamente definidos por edital (Araújo \& Othon, 2015).

Considerando-se todos esses benefícios, o artigo $4^{\circ}$, do Decreto Federal no 5.450/2005, determinou que, nas licitações para aquisição de bens e serviços comuns, será obrigatória a modalidade pregão, sendo preferencial a utilização da sua forma eletrônica (Araújo \& Othon, 2015).

Neste cenário é necessário que os municípios se adequem, pois a utilização do pregão nos municípios importará na transformação da rotina burocrática e, consequentemente, no aumento significativo da eficiência administrativa (Araújo \& Othon, 2015). Com essa modernização do processo licitatório, vislumbra-se também um aparato técnico para a condução do certame, envolvendo os recursos tecnológicos e as pessoas que fazem parte do setor responsável a fim de se obter resultados satisfatórios no processo.

Com toda clareza, a implementação da modalidade pregão nas licitações brasileiras foi o marco inovativo para as compras públicas, uma vez que se pode tratar o assunto com maior transparência, ampliando competitividade, maior possibilidade de redução de custos, bem como o acesso à informação muito mais acessível a população, que é a maior beneficiária, uma vez que pode visualizar lances, a disputa toda por meio eletrônico, no caso da modalidade eletrônica (Cavalcante \& et al., 2017). Por intermédio do Decreto ${ }^{\circ} 5.450$, o procedimento denominado pregão passa a ser operado de forma eletrônica, representando um dos maiores avanços no processo de aquisição por parte do Poder Público, dinamizando sua operacionalização e ampliando ainda mais a possibilidade de participação de concorrentes (Araújo \& Othon, 2015).

O Pregão Eletrônico foi regulamentado pelo Decreto Federal n ${ }^{\circ}$ 5.450/05 e pelo Decreto Federal $n^{\circ}$ 5.504/05, no entanto os referidos decretos não dispunham da obrigatoriedade de adoção no âmbito municipal, assim no dia 20 de setembro de 2019, o Governo Federal publicou o Decreto n 10.024, que regulamenta a licitação, o pregão na forma eletrônica, para a aquisição de bens e a contratação de serviços comuns, bem como revoga os decretos 5.450 e 5.504 ambos de 2005 (Brasil, 2005; 2019).

Segundo Mourão (2015) o Pregão eletrônico busca trazer para a Administração Pública as vantagens da virtualidade, 
destacando entre elas, a ampliação da competitividade induzida pela redução dos custos por parte dos licitantes, que não precisam mais se deslocar ao local da realização da sessão pública de licitação para apresentar suas propostas e lances, bem como pela facilidade no acompanhamento, pela Internet, de todo o processo do pregão eletrônico.

De acordo o art. $1^{\circ}$ do Decreto Federal n ${ }^{\circ} 10.024 / 19$, a utilização do Pregão Eletrônico é obrigatória para todos os órgãos da administração pública federal direta, pelas autarquias, pelas fundações e pelos fundos especiais, já no art. $5^{\circ}$ deste decreto diz que o Pregão eletrônico será realizado por meio do Sistema de Compras do Governo federal, disponível no endereço eletrônico www.comprasgovernamentais.gov.br (Brasil, 2019).

Nesse contexto, foi editada a Instrução Normativa 216/2019 que estabelece os prazos para que órgãos e entidades da administração pública estadual, distrital ou municipal, direta ou indireta, utilizem obrigatoriamente a modalidade de pregão, na forma eletrônica, conforme estabelecido na tabela 1.

Tabela 1 - Prazos para utilização do pregão na forma eletrônica

\begin{tabular}{|c|c|c|c|}
\hline 2019 & \multicolumn{3}{|c|}{2020} \\
\hline \multirow[t]{5}{*}{ 28/10/2019 } & $03 / 02 / 2020$ & $06 / 04 / 2020$ & $01 / 06 / 2020$ \\
\hline & \multicolumn{3}{|c|}{ Estados e DF } \\
\hline & \multicolumn{3}{|c|}{ Municípios + 50 mil habitantes } \\
\hline & & \multicolumn{2}{|c|}{ Municípios + 15 mil até 50 mil habitantes } \\
\hline & \multicolumn{3}{|c|}{ Municípios - 15 mil habitantes } \\
\hline
\end{tabular}

Fonte: Elaborado pelos autores (2020).

Desse modo, o pregão eletrônico tem se mostrado uma modalidade licitatória como um meio muito eficiente, pois é verificada somente a documentação do licitante vencedor e não de todos os participantes, ocorrendo a inversão das fases, tornando assim o processo mais célere.

Uma das vantagens na utilização do Pregão Eletrônico é a transparência no processo licitatório, o qual tem como objetivo evitar prática de fraudes e corrupção, pois todo o processo é acompanhado através da internet, facilitando a fiscalização já que todo o processo é informatizado (Figueiredo \& Costa, 2019). Conforme o art. $11^{\circ}$ do Decreto no 10.024/19, qualquer interessado pode acompanhar o desenvolvimento do processo licitatório em tempo real por meio da internet, e normalmente a identidade dos autores dos lances não é revelada aos demais concorrentes, evitando fraudes no processo (Figueiredo \& Costa, 2019).

E como já esperado, no último dia 01.04.2021 foi publicada a Lei $n^{\circ} 14.133$, que revoga integralmente a Lei ${ }^{\circ}$ 10.520/02 bem como a própria Lei Geral de Licitações, revogando diversas modalidades de licitação, no entanto o Pregão eletrônico foi mantido, inclusive ampliando as possibilidades de utilização, demonstrando, portanto, que atualmente é a modalidade de licitação mais eficiente e célere no campo das contratações públicas.

No intuito de demonstrar a eficiência do Pregão Eletrônico, o Serviço Brasileiro de apoio às Micro e Pequenas Empresas (SEBRAE) elaborou um quadro comparativo entre o Pregão Presencial e o Eletrônico afim de comprovar as vantagens na utilização por meio eletrônico, dentre elas, a que mais se destacou foi a ampliação da competitividade entre os licitantes, gerando como benefício para a Administração Pública, a obtenção a proposta mais vantajosa. Pôde-se constatar que a disputa de preço foi maior, houve uma redução significativa de preços, além do incentivo às micro e pequenas empresas a participarem desta modalidade eletrônica pois evita os gastos com deslocamento, diárias, alimentação dentre outros (Sebrae, 2017). 
Analisando a pesquisa realizada em processos licitatórios na modalidade de pregão eletrônico no Banco do Brasil, houve uma redução significativa nos preços dos produtos licitados, chegando a uma economia geral de $27,71 \%$ quando calculada por meio da diferença entre os valores das melhores propostas e os valores contratados, foi identificado que o aumento nos descontos auferidos podem estar associados à atividade de negociação exercida pelo pregoeiro (Andrade \& et al., 2017). A redução dos preços também pode ser associada a ampliação da competitividade, uma vez que empresas de todos os lugares podem concorrer às licitações de dentro da sua própria empresa, evitando gastos com deslocamento, o que em alguns casos inviabiliza a participação de algumas empresas (Andrade \& et al., 2017).

Em estudos análogos a estes desenvolvidos nos departamentos de licitações da Prefeitura Municipal de Viçosa e da Universidade Federal de Viçosa, em Minas Gerais, constatou-se que a média de redução de preços do pregão eletrônico é de $23,47 \%$ contra $18,25 \%$ do pregão presencial, demonstrando maior potencial de economia, racionalização dos procedimentos, redução de preços pagos e maior transparência, já que é uma disputa aberta via web (Faria \& et al., 2011).

Nesse sentido ainda, o Tribunal de Contas da União tem o pregão eletrônico como uma ferramenta útil para as aquisições públicas e, enquanto utensílio eficiente, seu uso deve ser priorizado, por uma série de fatores, que se somam e que podem ser resumidos em (1) argumentos de eficiência - pela adequação do processo licitatório aos anseios de celeridade e de simplificação de rito; (2) argumentos econômicos, pela possibilidade de redução dos preços de compra; (3) pela legalidade (Andrade \& et al., 2017).

Assim, pela facilidade de acesso virtual ao certame e a suas informações, através de editais, resultados, recursos e andamento de processos, o pregão eletrônico, se tornou uma das ferramentas mais transparentes na Administração Pública, disponibilizando maior participação popular no acompanhamento do certame, além de trazer maior economicidade, o que resulta em um maior controle sobre os recursos públicos utilizados pela Administração Pública, agindo também como um mecanismo ativo de prevenção à corrupção e ao crime, obstando a prática de fraudes e desvio dos recursos públicos (Sobral \& Neto, 2020).

\section{Análise Interpretativa}

Após a leitura e desenvolvimento teórico desse artigo, foi possível realizar uma análise interpretativa que também levou em consideração os termos de busca considerados na metodologia.

O modelo gerencial baseado nos pressupostos da competição do setor privado tem como princípios norteadores o planejamento estratégico, objetivos, descentralização, accountability, interesse público, participação social, transparência, honestidade, liderança e eficiência. Após a década de 1990 a administração pública brasileira modificou sua busca pela eficiência e passou a realizar ações orientadas para o "cliente-cidadão", cujo objetivo passou a ser o interesse público e não o lucro.

As ideias de tornar a administração mais flexível, os administradores autônomos com relação a normas rígidas, supervisão direta e mais responsáveis perante o núcleo estratégico do Estado, perante a sociedade e mais motivados através da descentralização da administração por meio de objetivos e indicadores de desempenho permitiu tornar mais forte o núcleo estratégico do Estado e mais eficazes o uso das organizações da sociedade civil e conselhos de cidadãos para manter os serviços públicos e os funcionários públicos sob controle.

O Estado passou a desempenhar o papel de estimulador de práticas democráticas e de participações comunitárias, enquanto a sociedade civil passou a fiscalizar o papel do Estado. A Nova Administração Pública entende a gerência como um meio de usar a habilidade político-administrativa para atingir a excelência nos serviços públicos.

A reforma gerencial, referenciada pela lógica do setor privado, focada no alcance de resultados a partir de metas preestabelecidas ainda não é a realidade da totalidade da federação, dos estados e principalmente dos municípios de pequeno 
porte. A administração pública brasileira ainda convive com a forte presença do patrimonialismo na política da administração, além de não ter sido capaz de resolver algumas dinâmicas políticas. A lógica gerencial do setor privado é incompatível com o interesse público, por isso, há também a dificuldade de adaptação das técnicas do setor privado ao setor público. A complexidade dos sistemas administrativos ainda reflete a realidade tecnocrata do modelo burocrático, que cumpriu a sua missão e teve a sua importância para a estruturação do aparelhamento estatal, porém, atualmente contribui para o comprometimento da efetividade que se espera do Estado em cumprir o seu papel (Araújo \& Pereira, 2012).

A administração pública não tem liberdade e nem vontade pessoal, só pode fazer o disposto em lei, seguindo o princípio da legalidade. O princípio da impessoalidade diz que a atividade administrativa deve ser dirigida aos cidadãos em geral, sem favoritismos, discriminações benéficas ou prejudiciais. O princípio da moralidade impõe à Administração uma atuação moral administrativa, pautada na ética, honestidade, lealdade e boa-fé. O princípio da publicidade visa garantir o controle da gestão administrativa através da sociedade, a fim de conferir à mesma validade e eficácia. O princípio da eficiência está ligado à finalidade de alcançar os melhores resultados na gestão pública da forma mais adequada. A busca por eficiência se dá em conseguir um melhor resultado com os mesmos recursos ou até mesmo com menos recursos.

O Pregão Eletrônico está alicerçado no princípio da eficiência, uma vez que devido a sua clareza, otimização dos custos e celeridade nas realizações das contratações públicas, essa modalidade de licitação tem se mostrado como um modelo ideal para que Administração Pública possa celebrar contratos. Tal relevância foi reforçada no dia 01.04.2021, quando foi publicada a nova lei de licitações, onde se revoga algumas modalidades de licitação, tais como: Carta Convite, Tomada de preços, o RDC - Regime diferenciado de contratações públicas, inclusive a Lei no 10.520/02 que regulamenta o Pregão. No entanto, a nova Lei ${ }^{\circ}$ 14.133/21, recepcionou a modalidade de Pregão, e tornou a sua forma eletrônica como obrigatória, bem como, ampliou a sua abrangência, entendendo assim, que o Pregão Eletrônico é a forma mais eficiente de celebrar contratos junto a Administração Pública.

Atualmente, o Pregão eletrônico é obrigatoriamente utilizado para aquisição de bens e serviços comuns, bem como, para realizar contratações de serviços de engenharia denominados comuns, pequenos reparos de manutenção e adequação de bens móveis e imóveis, desde que seja preservado a estrutura original. Deste modo, o Pregão Eletrônico apresenta um grande avanço em nosso ordenamento jurídico, tratando-se de instrumento vanguardista de grande valia para as contratações contemporâneas e também de significativa importância no balizamento de legislações futuras.

As vantagens da utilização do pregão na forma eletrônica, podem ser demonstradas por meio da ampliação da competitividade entre os fornecedores, considerando que a licitação ocorre de forma online em plataformas disponibilizadas pelo governo, bem como, por empresas particulares, facilitando assim a participação das empresas, dispersas geograficamente. Além disso, considerando que os licitantes não precisam se deslocar, a mesma empresa poderá participar de diversas licitações simultaneamente de dentro da sua própria empresa. Também cabe destacar, a ampliação da transparência, uma vez que pessoas de qualquer lugar podem acompanhar a sessão da licitação, bem como, todos os atos ali praticados ficam registrados, inibindo a prática de atos de corrupção, praticados por licitantes e/ou servidores públicos.

Falando em eficiência no pregão eletrônico, não poderia deixar de ressaltar a novidade advinda pela nova Lei de licitações e contratos $n^{\circ}$ 14.133/21, que é a possibilidade de realizar contratações de serviços comuns de engenharia, uma vez que os serviços de engenharia não poderiam ser licitados por meio de pregão, considerando que esta modalidade era restrita para licitações para aquisição de bens e serviços comuns.

Grande tem sido o esforço da administração pública brasileira para aprimorar sua estrutura administrativa, entretanto, para concretizar ações de interesse público orientadas para o bem estar do cidadão, é preciso superar barreiras políticas, ideológicas e corporativas existentes no âmbito das instituições e organizações públicas, e principalmente, capacitar e qualificar os gestores públicos com base nos pressupostos do modelo gerencial. 


\section{Considerações Finais}

Assim como a administração pública brasileira, a forma de licitação passou por transformações com o passar dos anos. Desde os primeiros registros de compras feitas a partir de licitação, em especial destaque para o Pregão, onde utilizava-se o sistema da "Vela e Pregão" para receber lances que ofertassem os menores preços, dentro de um sistema totalmente patrimonialista, objetivando a aquisição de bens para benefício econômico e financeiro do clero e da nobreza, até os dias de hoje com a utilização do Pregão Eletrônico. Este sistema totalmente informatizado utiliza a internet como meio para dar transparência ao processo licitatório.

Desse modo, o presente trabalho buscou descrever o Pregão eletrônico como um instrumento para o atendimento do princípio da eficiência na administração pública. Como resposta ao problema de pesquisa - Quando observado o princípio da eficiência, como a administração pública pode se beneficiar das ferramentas proporcionadas pelo pregão eletrônico? -, e atendimento ao objetivo proposto, destaca-se que:

- Existe um alinhamento entre os construtos citados sobre a administração pública, princípio da eficiência e a necessidade das ferramentas que constituem o pregão eletrônico para a celeridade, transparência, otimização dos custos e demais benefícios proporcionados pelo pregão eletrônico;

- A presença da inversão de fases no processo licitatório, onde, primeiramente, se julga as propostas e, posteriormente, analisa os documentos das empresas vencedoras. Ademais, observa-se o prazo recursal em momento único e de publicação do edital reduzido

- O pregão eletrônico é considerado uma grande evolução no processo de contratações públicas em termos de eficiência, transparência e agilidade de acesso em comparação aos meios tradicionais disponíveis. Assim, espera-se que ele se torne cada vez mais referência nas contratações públicas.

\section{Propostas para pesquisas futuras}

Tendo em vistas que este ensaio é teórico, as reflexões neles obtidas abrem caminho para que novos estudos empíricos sejam realizados, podendo ser analisada tanto a percepção de gestores públicos como a de representantes de organizações fornecedoras que participam de pregões eletrônicos. Por meio de metodologias que utilizem da análise documentos, entrevistas e aplicação de questionários é possível aprofundar o entendimento sobre as motivações das empresas concorrentes, etapas do processo licitatório e benefícios auferidos por ambas as partes envolvidas.

\section{Referências}

Abreu, A.C. D., Helou, A. R. H., \& Fialho, F. A. P. (2013). Possibilidades epistemológicas para a ampliação da Teoria da Administração Pública: uma análise a partir do conceito do Novo Serviço Público. Cad. EBAPE.BR, v. 11 (4), 613-620. doi:10.1590/S1679-39512013000400009.

Abrucio, F. L. (2007). Trajetória recente da gestão pública brasileira: um balanço crítico e a renovação da agenda de reformas. Revista de Administração Pública. Edição Especial Comemorativa, 67-86. Obtido em: https://www.scielo.br/pdf/rap/v41nspe/a05v41sp.pdf

Andion, C. (2012). Por uma nova interpretação das mudanças de paradigma na administração pública. Cad. EBAPE.BR, v. 10(1), 1-19. http://bibliotecadigital.fgv.br/ojs/index.php/cadernosebape/article/view/5243/3977

Andrade, F. A. Pregão Eletrônico como Mito Racional. Análise dos Processos Licitatórios do Banco do Brasil. https://www.revistas.unijui.edu.br/index.php/desenvolvimentoemquestao/article/view/4326

Araújo, P. G. D., \& Pereira, J. R. (2012). Análise da aplicabilidade do modelo gerencial na administração municipal. Revista de Administração Pública, 46, 1179-1199. doi: 10.1590/S0034-76122012000500001

Araújo, R. M. D. \& Othon, M. D. L. P. (2015). Compras públicas no âmbito do sistema de pregão: um estudo com funcionários públicos. Diálogo, 169-190. https://revistas.unilasalle.edu.br/index.php/Dialogo/article/view/2238-9024.15.20

Brasil. C. R. F. B. (1988) Presidência da República. Brasília. http://www.planalto.gov.br/ccivil_03/constituicao/constituicao.htm

Brasil. E. C. № 19, de 04 de junho de (1998). Modifica o regime e dispõe sobre princípios e normas da Administração Pública, servidores e agentes políticos, controle de despesas e finanças públicas e custeio de atividades a cargo do Distrito Federal, e dá outras providências. Diário Oficial [da] República Federativa 
do Brasil. Obtido em: http://www.planalto.gov.br/ccivil_03/constituicao/Emendas/Emc/emc19.htm\#art6

Bresser-Pereira, L. C. (2008). O modelo estrutural de gerência pública. Revista de Administração Pública, v. 42 (2), 391-410. doi:10.1590/S003476122008000200009 .

Camargo, F. O. \& Guimarães, K. M. S. (2013). O princípio da eficiência na gestão pública. Revista CEPPG-CESUC-Centro de Ensino Superior de Catalão, v. 28. http://www.portalcatalao.com/painel_clientes/cesuc/painel/arquivos/upload/downloads/376b38ef01c9b0caae5d67f8c6bf4d03.pdf .

Campelo, G. S. B. (2010). Administração pública no Brasil: ciclos entre patrimonialismo, burocracia e gerencialismo, uma simbiose de modelos. Ciência \& Trópico, v. 34 (2). Obtido em: https://fundaj.emnuvens.com.br/CIC/article/view/871.

Carvalho Filho, J. S. (2012). Manual de direito administrativo. (25. ed. rev. ampl. e atual.). até a Lei no 12.587, de 3-1-2012. São Paulo: Atlas.

Cavalcante, S. D. O. R. Silva, L. I. D. P. D. Centenaro \& M. Zamberlan, C. O. (2017). Análise Do Pregão Eletrônico E Presencial Na Universidade Estadual De Mato Grosso Do SuL. Revista Práticas de Administração Pública, v. 1 (1), 119-138. Obtido em: https://periodicos.ufsm.br/pap/article/view/25878.

Cervo, A. L., Bervian, P. A. \& Da Silva, R. Metodologia científica. (6. ed). São Paulo: Cortez, 2013.

Cretella Júnior. José (1999). Licitações e Contratos do Estado. (2. ed.) Forense.

Cury-Mendes, C. C. (2015). Princípios do processo administrativo federal e a formalidade dos atos processuais: uma discussão com foco no desenvolvimento. Revista Brasileira de Planejamento e Desenvolvimento, 4 (41), 132-147. https://periodicos.utfpr.edu.br/rbpd/article/view/3528/2778.

Decreto $\mathrm{n}^{\circ}$ 10.024, de 20 de setembro de 2019. (2019). Regulamenta a licitação, na modalidade pregão, na forma eletrônica, para a aquisição de bens e a contratação de serviços comuns, incluídos os serviços comuns de engenharia, e dispõe sobre o uso da dispensa eletrônica, no âmbito da administração pública federal. Diário Oficial [da] República Federativa do Brasil. Obtido em: http://www.planalto.gov.br/ccivil_03/_ato2019-2022/2019/decreto/D10024.htm.

Decreto $\mathrm{n}^{\circ} 3.555$, de 8 de agosto de 2000. (2000). Aprova o regulamento para a modalidade de licitação denominada pregão, para aquisição de bens e serviços comuns. Diário Oficial [da] República Federativa do Brasil. Obtido em http://www.planalto.gov.br/ccivil_03/decreto/D3555.htm

Decreto $\mathrm{n}^{\circ}$ 5.450, de 31 de maio de 2005. (2005). Regulamenta o pregão, na forma eletrônica, para aquisição de bens e serviços comuns, e dá outras providências. Diário Oficial [da] República Federativa do Brasil. Obtido em: http://www.planalto.gov.br/ccivil_03/_Ato2004-2006/2005/Decreto/D5450.htm

Decreto $\mathrm{n}^{\circ}$ 5.504, de 5 de agosto de 2005. (2005). Estabelece a exigência de utilização do pregão, preferencialmente na forma eletrônica, para entes públicos ou privados, nas contratações de bens e serviços comuns, realizadas em decorrência de transferências voluntárias de recursos públicos da União, decorrentes de convênios ou instrumentos congêneres, ou consórcios públicos. Diário Oficial [da] República Federativa do Brasil. http://www.planalto.gov.br/ccivil_03/_ato2004-2006/2005/decreto/d5504.htm

Di Pietro, M. S. Z. (2001). Direito administrativo. (13. ed.) Atlas.

Faria, E. R., Ferreira, M. A. M., Santos, L. M. D., \& Silveira, F. R. S (2011). Pregão eletrônico versus pregão presencial: estudo comparativo de redução de preços e tempo. Revista de Contabilidade do Mestrado em Ciências Contábeis da UERJ (online), Rio de Janeiro, 16(1), 47-62. Disponível em: https://www.epublicacoes.uerj.br/index.php/rcmccuerj/article/view/5478.

Figueiredo, J. I. E., \& Costa, A. V. (2019). Vantagens do Pregão Eletrônico. Revista de Psicologia, 13(43), 845-864. https://idonline.emnuvens.com.br/id/article/view/1566.

Granato, L. (2018). O campo de estudos de administração pública e as abordagens do problema da corrupção: possíveis interlocuções. Revista E-legis, Brasília, n. 25, p. 42-57.

Harger, M. (1999) Reflexões iniciais sobre o princípio da eficiência. Revista de Direito Administrativo, 217, 151-161. doi.org/10.12660/rda.v217.1999.47421

Instrução Normativa $n^{\circ}$ 206, de 18 de outubro de 2019. (2019). Estabelece os prazos para utilizar obrigatoriamente a modalidade de pregão, na forma eletrônica. Obtido em: https://www.in.gov.br/en/web/dou/-/instrucao-normativa-n-206-de-18-de-outubro-de-2019-222816417.

Lei 10.520, de 17 de julho de 2002. (2002). Institui, no âmbito da União, Estados, Distrito Federal e Municípios, nos termos do art. 37, inciso XXI, da Constituição Federal, modalidade de licitação denominada pregão, para aquisição de bens e serviços comuns, e dá outras providências. Diário Oficial da República Federativa do Brasil. Obtido em: http://www.planalto.gov.br/ccivil_03/leis/2002/110520.htm.

Lei 8.666, de 21 de junho de 1993. (1993). Regulamenta o art. 37, inciso XXI, da Constituição Federal, institui normas para licitações e contratos da Administração Pública e dá outras providências. Diário Oficial da República Federativa do Brasil. http://www.planalto.gov.br/ccivil_03/leis/18666cons.htm.

Leite, R. V. (2001). O princípio da eficiência na administração pública. Revista de direito administrativo, 226, 251-264. doi.org/10.12660/rda.v226.2001.47245

Marrara, T. (2014). As fontes do direito administrativo e o princípio da legalidade. Revista Digital de Direito Administrativo, vol. 1(1), 23-51. https://www.revistas.usp.br/rdda/article/view/73561

Martins, E., Dias, C. A., Santos, C. M., Souza, M. C., \& Gomes, L. S. (2021). Análise integrativa do processo administrativo disciplinar e do princípio da eficiência. Research, Society and Development, v. 10 (4), e29610414124. doi:10.33448/rsd-v10i4.14124

Medauar, O. (2011). Direito administrativo moderno. (15. ed.). Revista dos Tribunais.

Moraes, A. (1999). Direito constitucional. (5 ed. rev., ampl. e atual.). Atlas.

Morais, J. (2009). Princípio da eficiência na Administração Pública. ETHOS JUS: revista acadêmica de ciências jurídicas, 3(1), 99-105. https://www.eduvaleavare.com.br/wp-content/uploads/2014/07/principio_eficiencia.pdf 
Research, Society and Development, v. 10, n. 9, e43210918212, 2021

(CC BY 4.0) | ISSN 2525-3409 | DOI: http://dx.doi.org/10.33448/rsd-v10i9.18212

Mourão, R. P. (2015). Celso Furtado e a questão do patrimonialismo no Brasil. Teoria \& Pesquisa: Revista de Ciência Política, 24 (1). http://www.teoriaepesquisa.ufscar.br/index.php/tp/article/download/428/281

Paes de Paula, A. P. (2005) Administração Pública Brasileira: entre o gerencialismo e a Gestão Social. Revista de Administração de Empresas, 45 (1), $36-52$. doi: $10.1590 / \mathrm{S} 0034-75902005000100005$

Pedraja-Chaparro, F., \& Salinas-Jiménez, J., \& Smith, Peter C. (2005). Assessing public sector efficiency: Issues and methodologies. Available at SSRN 2018855. doi: $10.2139 / \mathrm{ssrn} .2018855$

Pereira Júnior, J. T. (2003). Comentários à Lei das Licitações e Contratações da Administração Pública. Renovar, 201.

Ribeiro, G. L. V. (2007). A evolução da licitação. Portal da classe contábil, v. 21. Obtido em: https://egov.ufsc.br/portal/sites/default/files/anexos/2110321104-1-PB.pdf

Rigolin, I. B. (2008). Manual prático das licitações. São Paulo: Saraiva, 192.

Rocha, J. D. A. (1995). Estudos sobre o Poder Judiciário. Malheiros.

Sebrae. (2017). Pregão Presencial e Eletrônico. - Brasília. https://www.gov.br/compras/pt-br/assuntos/fornecedores/midia/prego-presencial-e-eletrnico.pdf

Sobral, P., \& Neto, R. (2020). O Pregão Eletrônico Como Ferramenta de Eficiência na Gestão Pública. International Journal of Professional Business Review, 5 (1), 60-71. http://www.spell.org.br/documentos/ver/59230/o-pregao-eletronico-como-ferramenta-de-eficiencia-na-gestao-publica--/i/pt-br

Severino, A. J. (2013). Metodologia do trabalho científico. Cortez.

Souza, R. L., Santos, A. T. de O., Dias, C. A., \& Santos, C. M. (2020). Contributions of human performance evaluations to the achievement of objectives in the public sector. Research, Society and Development, v. 9 (4), e96942881. https://doi.org/10.33448/rsd-v9i4.2881

Teixeira, R. R., Dias, C. A., Santos, C. M., \& Barros, G. F. (2021). Instrumentos de caráter jurídico e técnico de suporte à adoção do programa de despesas públicas e responsabilidade financeira (PEFA) na avaliação da gestão das finanças públicas municipal. Research, Society and Development, 10(4), e4010413663. https://doi.org/10.33448/rsd-v10i4.13663 